\title{
A necessidade de motivação da dispensa do empregado público: observância aos princípios constitucionais da legalidade, moralidade e impessoalidade
}

\author{
Oscar Krost ${ }^{*}$ \\ [...] em todos os momentos da história, o direito é \\ constituído por uma tensão entre regulação \\ (autoridade) e emancipação (razão), mas, com o \\ desenrolar da experiência humana, a \\ emancipação triunfa sobre a regulação. \\ Boaventura de Sousa Santos
}

\section{INTRODUÇÃO}

Apresenta-se como uma das questões mais tormentosas atualmente ao Direito do Trabalho a resolução de conflitos decorrentes de relações firmadas entre a Administração Pública e seus trabalhadores, quando adotado o regime contratual, disciplinado pela Consolidação das Leis do Trabalho.

Tal fenômeno se configura, principalmente, pela colocação em choque de valores caros a dois ramos distintos do saber jurídico, marcados pela defesa de interesses antagônicos

\footnotetext{
* Professor substituto do Departamento de Direito Econômico e do Trabalho da Faculdade de Direito da UFRGS.

1 SANTOS, Boaventura de Sousa. Para um novo senso comum: a ciência, o direito e a política na transição paradigmática. São Paulo: Cortez, 2001, v. 1 - A crítica da razão indolente: contra o desperdício da experiência, p. 129.
} 
e de difícil conciliação, como o são o Direito Administrativo e do Trabalho. ${ }^{2}$

Dentre os pontos mais polêmicos se encontra a questão sobre a existência de garantia do posto de trabalho por parte do empregado público, pela aplicação do art. 41 da Constituição, dividindo-se a doutrina e a jurisprudência dos Tribunais Superiores.

Diante de tais fatos, por meio de uma interpretação calcada em inúmeras disposições que integram o sistema normativo, propõe-se uma releitura crítica do tratamento dispensado ao tema, examinando o conceito de empregado público, sua forma de contratação e de dispensa, bem como os fundamentos favoráveis à necessidade de motivação do ato que promova o seu desligamento, lançando mão, para tanto, de textos normativos e doutrinários, além de subsídios jurisprudenciais.

\section{EMPREGADO PÚBLICO. CONCEITO. CONTRATAÇÃO E DISPENSA. VEDAÇÃO Å DESPEDIDA IMOTIVADA}

Por empregado público tem-se o ocupante de emprego mantido com o Estado, em modalidade de "núcleos de encargos de trabalho permanentes a serem preenchidos por agentes contratados para desempenhá-los, sob relação trabalhista". 3

Integra a espécie do gênero servidor público, o qual compreende, ainda, os "estatutários", regidos por estatuto próprio e que ocupam cargos, e os trabalhadores disciplinados por regime especial, também conhecido por administrativo, que podem estar vinculados tanto a cargos, quanto a empregos, de acordo com a lei instituidora do respectivo posto de trabalho.

2 Dimensionando com peculiar precisão a complexidade com que se imbui o tema, leciona Carmen Camino: "Mais de vinte anos de experiência na magistratura do trabalho autorizam-nos a expressar nossa total discordância com a adoção do regime dito 'celetista', ou 'celetário', para o provimento de postos de trabalho no âmbito da Administração Direta, diante da sua substancial incompatibilidade com os objetivos e com a natureza do serviço público. [...] Essas intransponiveis dificuldades têm martirizado os juizes do trabalho, às voltas com ações de servidores públicos, nas quais invocados principios próprios do direito do trabalho, muitas vezes colidentes com os principios regentes da Administração Pública. Apenas para ficarmos num único entre os tantos exemplos, imaginemos o, talvez, mais freqüente, do servidor pleitear incorporação de direitos à luz do art. 468 da CLT, inspirado na preservação da condição mais benéficauma das faces do princípio da proteção, diante de nova lei que venha alterar determinado aspecto das condições de trabalho, por absoluta necessidade de atender ao interesse público. A que princípio o juiz atenderá? A que interesse dará prevalência? " (CAMINO, Carmen. Direito Individual do Trabalho. Porto Alegre: Síntese, 2003, p. 306-307).

3 BANDEIRA DE MELLO, Celso Antônio. Curso de Direito Administrativo. São Paulo: Malheiros, 2001, p. 235. 
Como requisito de acesso a cargo ou a emprego público, a partir da Constituição de 1988, por seu art. 37, inciso II, exige-se a prévia aprovação em concurso, de provas ou de provas e títulos, quanto a liames a prazo indeterminado. Encontram-se excetuadas de tal exigência apenas duas hipóteses: a de contratação emergencial, a prazo certo, nos termos estabelecidos em lei específica, para atendimento de necessidade temporária de excepcional interesse público, e a de nomeação para cargos em comissão, de livre investidura e exoneração, nos termos dos incisos II e IX do dispositivo antes referido, atinente à Carta Política.

Quanto à forma de dispensa dos trabalhadores públicos admitidos a prazo indeterminado, após aprovação em certame, duas situações se apresentam, de acordo com o regime jurídico.

Àqueles disciplinados por estatuto é vedada a livre exoneração, em face da estabilidade obtida após aprovação em estágio probatório de três anos, nos moldes previstos no art. 41 da Constituição. Somente podem ser desligados em virtude de sentença judicial transitada em julgado, após a realização de processo administrativo ou de procedimento de avaliação periódica de desempenho, sendo nestas duas últimas situações necessário assegurar-lhes o exercício da ampla defesa, nos termos do parágrafo $1^{\circ}$ do artigo mencionado, ou, ainda, em face da necessidade de adequação aos limites de despesas com pessoal, nos termos previstos no art. $169, \S 4^{\circ}$, da Lei Maior.
De outro lado, não tão pacífica se mostra a situação dos trabalhadores regidos pela CLT. Atualmente a doutrina e a jurisprudência traçam como critério de distinção para fins de definição sobre a existência ou não de impedimento contra a despedida do empregado público a alocação de seu empregador na estrutura organizacional do Estado.

Se contratado pela Administração direta, autárquica ou fundacional federal, estaria tal trabalhador ao abrigo de uma espécie singular de garantia, contra a dispensa imotivada, ressalvada a prática de falta grave, nos termos previstos no art. 482 da CLT, de acumulação ilegal de cargos, empregos ou funções públicas, da necessidade de redução do quadro de pessoal, para adequação ao limite de despesas, ou por insuficiência de desempenho, conforme art. $2^{\circ}$ da Lei $n^{\circ} 9.962 / 2000$. Em semelhante sentido, porém, atingindo os quadros dos Estados, Distrito Federal e Municípios, e por fundamento diverso, encontra-se pacificado no TST o entendimento sobre a aplicação a estes empregados públicos do art. 41 da Constituição, consoante súmula 390 , item $\mathrm{I}$.

Entretanto, se como empregador figurar uma empresa pública ou uma sociedade de economia mista, majoritariamente está sedimentada a posição que não apenas não estariam os empregados protegidos contra a dispensa, como o ato que a determinar não necessitaria de motivação expressa. 
Nota-se claramente a existência de disparidade de tratamento não apenas entre desiguais, fato imposto pela distinção evidente entre "estatutários" e "celetistas", em função do regime jurídico adotado. Verifica-se a dispensa de trato nitidamente diferenciado entre semelhantes, dando margem à criação de uma subcategoria de trabalhador regido pela CLT.

$\mathrm{O}$ ato de dispensa do empregado público, independente de ser o empregador integrante da Administração direta ou não, deve ser analisado como categoria de ato administrativo, de cunho discricionário, na medida em que praticado pelo Estado ou por quem lhe faça as vezes, sendo-lhe oportunizada a elaboração de um juízo de conveniência e oportunidade para sua efetivação, podendo, ainda, eleger os respectivos motivos.

Encontra-se sujeito aos princípios da impessoalidade e da moralidade, moderados pelo princípio da legalidade, positivados no art. 37, caput, da Constituição, de cuja análise conjunta depreende-se a existência de vedação pelo sistema ao desligamento dos quadros públicos de um dado trabalhador por interesse pessoal do administrador ou por afronta aos valores morais que devem orientá-lo, em oposição à finalidade do Estado, como bem exposto por Celso Antônio Bandeira de Mello:
Assim, como a contratação de pessoal nas empresas públicas e sociedades de economia mista sofre o condicionamento aludido, também não é livre o desligamento de seus empregados. Cumpre que haja razões prestantes e demonstráveis para efetuá-lo, já que seus administradores não gerem negócio particular, onde prepondera o princípio da autonomia da vontade, mas conduzem assunto de interesse de toda a coletividade, cuja gestão sempre reclama adscrição à finalidade legal pré-estabelecida, exigindo, pois transparência, respeito à isonomia e fundamentação satisfatória para os atos praticados. Daí que a despedida de empregado demanda apuração regular de suas insuficiências ou faltas, com direito à defesa e, no caso de providências amplas de enxugamento de pessoal, prévia divulgação dos critérios que presidirão as dispensas, a fim de que se possa conferir a impessoalidade das medidas concretamente tomadas.

Perante dispensas ilegais, o empregado terá direito à reintegração no emprego, e não meramente indenização compensatória, pois não estão em pauta interesses privados, mas sobretudo o princípio da legalidade da Administração, o qual é garantia de todos os cidadãos e ao qual, portanto, todos fazem jus. ${ }^{4}$

Inexiste nos Direitos administrativo e constitucional hipótese que autorize a prática de ato de qualquer espécie que não se submeta direta ou 
indiretamente ao crivo dos princípios e das regras que orientam estes campos do conhecimento, ${ }^{5}$ ainda que se admita a possibilidade de exercício de autonomia da vontade no Direito Público por parte dos agentes estatais no regular desempenho de suas atribuições.

Tese em contrário, daria margem à prática de atos não puramente discricionários, mas arbitrários, legitimando um processo de transposição do modus operandi do administrador, o qual estaria autorizado a fazer o que bem entendesse, sem a necessidade de justificar ou externar os motivos que o levaram a tanto, gerindo como seu o patrimônio público.

Ademais, sinale-se o teor dos arts. $7^{\circ}$, inciso I, $173, \S 1^{\circ}$, inciso II e 174 , todos da lei maior, que asseguram o direito do trabalhador ao emprego protegido contra despedida arbitrária ou sem justa causa, nos termos de Lei
Complementar, impondo a submissão do Estado ao regime jurídico das empresas privadas quando explorador direto da atividade econômica, servindo de indicativo aos particulares neste segmento atuantes, como agente normativo e regulador. Verifica-se com clareza a incumbência do Estado de servir como espécie "de norte" à atuação da iniciativa privada na esfera produtiva, demonstrando a possibilidade em uma sociedade democrática de se proceder à harmonização de fatores antagônicos, como a manutenção competitiva de um empreendimento com fins lucrativos e a valorização social do trabalho.

Em sede infraconstitucional, os arts. 422 e 472 do Código Civil ${ }^{6}$ impõem aos contratantes na conclusão e na execução dos negócios jurídicos a observância dos princípios da boa-fé e da função social dos contratos, bem como do paralelismo das formas, pelo

5 Paulo Bonavides, de forma elucidativa, esclarece a importância com que se revestem os princípios no sistema jurídico: "As regras vigem, os princípios valem; o valor que neles se insere se exprime em graus distintos. Os principios, enquanto valores fundamentais, governam a Constituição, o regímen, a ordem jurídica. Não são apenas a lei, mas o Direito em toda a sua extensão, substancialidade, plenitude e abrangência". (BONAVIDES, Paulo. Curso de Direito Constitucional. São Paulo: Malheiros, 2002, p. 260).

6 Manuel Alfredo Martins e Rocha, compartilhando desta posição, sustenta que "A denúncia vazia do contrato de trabalho na empresa pública agride o princípio maior da função social da empresa", concluindo ser "possivel a despedida do empregado não estável nas empresas estatais. Se, contudo, não houver observância, no ato da demissão, das normas legais, previstas no art. 37, 'caput', da Constituição Federal, isto é, legalidade, impessoalidade, moralidade e publicidade, o ato é nulo". (ROCHA, Manuel Alfredo Martins e. Servidor Público: empregado - estabilidade no emprego de trabalhadores nas empresas estatais - abuso de poder - atos nulos e atos anuláveis. Revista do Tribunal Regional do Trabalho da $16^{a}$ Região, São Luis, v. 2, n. 1, jun. 1993, p. 63. 
qual, "o distrato faz-se pela mesma forma exigida para o contrato". Sob este enfoque, conclui-se que se o ingresso nos quadros públicos se encontra condicionado à prévia aprovação em certame de provas ou de provas e títulos, a fim de resguardar a impessoalidade da contratação, por coerência e lógica, o mesmo entendimento deve pautar a terminação do vínculo, de modo a estar submetido a semelhante critério, eminentemente objetivo, sob pena de esvaziamento da própria intenção do constituinte, ao positivá-lo. Sendo o quesito preponderante para o ingresso no serviço público o mérito pessoal do candidato, igual valor deve ser adotado para orientar seu desligamento, admitidas, em situações excepcionais, como de imperiosa necessidade de redução de gastos com pessoal, a opção por outras medidas, sempre ligadas à tutela do interesse público.

$\mathrm{O}$ fato do empregador integrar ou não a Administração pública direta, autárquica ou fundacional não pode servir de amparo à dispensa de tratamento idêntico no curso da contratação e da execução do liame contratual, diferenciando-se, contudo, no momento de sua terminação, quanto à garantia da manutenção do vínculo, segundo entendimento do TST. Tal posição afronta o princípio isonômico, previsto no art. $5^{\circ}$, inciso II, da Constituição, criando duas categorias distintas de empregados públicos: uma, de primeiro nível, à qual é preservado o emprego, que somente pode ser "perdido" mediante verificação de inaptidão pessoal do trabalhador, por cometimento de falta ou por critérios objetivos, e outra, em um plano inferior, cujo contrato de trabalho pode ser desfeito sem qualquer justificativa, pela prática de espécie de ato administrativo sui generis, exime de qualquer motivação, não se submetendo aos cânones que regem o Direito Administrativo.

Outra decorrência da tolerância à livre dispensa dos empregados admitidos mediante aprovação em concurso, sem a necessidade da devida fundamentação, repousa sobre o impedimento de aplicação do comando inscrito no art. 37, inciso IV, da Carta Política, que assegura o direito à observância da ordem classificatória dos candidatos aprovados em certame público para fins de nomeação ou contratação, chancelando de forma velada a preterição dos mais bem classificados em benefício daqueles em pior situação, de forma amplamente discricionária e arbitrária. Para tanto, bastaria que o Administrador procedesse ao chamamento dos que estivessem à frente do candidato de sua predileção, nomeando-os e dispensando-os, sucessiva e injustificadamente, dia após dia, dentro do prazo de validade do concurso, até que seu intento fosse obtido.

Apenas em situações em que manifesta a ocorrência de desvio de finalidade ou abuso de poder seria possível o desmascaramento de fraudes desta natureza, na forma examinada no acórdão oriundo do TRT da 4 a Região, 
nos autos do processo $n^{\circ} 00481.024 / 00$ 0 , em que atuou como relator o Juiz José Cesário Figueiredo Teixeira, como se depreende dos termos de sua ementa:

EMENTA: BANCO DO BRASIL. NULIDADE DE DISPENSA DE EMPREGADO CONCURSADO. $A$ dispensa por empresa de economia mista de empregado contratado após aprovação em concurso público, no dia imediato ao da admissão, configura abuso de direito e ofensa à regra do art. 37, inciso I da Constituição Federal, pois viabiliza que o empregador escolha quais dentre os aprovados pretende efetivamente contratar. Prevalência desses princípios e da norma que os consagra, caput do referido art. 37 , sobre as disposições do art. 173, parágrafo $1^{\circ}$ da mesma Carta, e sobre as disposições consolidadas que tratam do contrato de experiência. Procedimento que atenta contra os princípios da moralidade e da impessoalidade que devem reger a administração pública direta $e$ indireta e que, por isso mesmo, não pode ser chancelado ( $7^{\mathrm{a}}$ Turma, publicado em 07/7/2003).

Por este conjunto de fatores cresce a cada dia, não apenas em sede doutrinária, o entendimento de que necessária a motivação, por mais singela que seja, do ato de dispensa do empregado público, admitido após aprovação em concurso, inclusive para fins de exercício do direito à ampla defesa do mesmo.

Neste sentido se pronunciou a Advocacia-Geral da União, ente constitucionalmente investido nas funções de consultoria e assessoramento do Poder Executivo, na forma disposta no art. 131, caput, da Constituição, como apura-se da indexação do Parecer $n^{\circ}$ CQ-64, de lavra de Obi Damasceno Ferreira:

SERVIÇOPÚBLICO-DISPENSA - MOTIVAÇÃO. Servidor admitido por concurso, conquanto regido pela Consolidação das Leis do Trabalho, não pode ser dispensado discricionariedade, sem motivação. Ato nulo, a configurar abuso de poder. Reintegração do interessado no emprego.?

Em mesma orientação existem decisões do STF, de lavra do Ministro Marco Aurélio Mendes de Farias Mello, tal como a exarada em exame sobre a possibilidade de se promover a despedida sem motivação de integrante do corpo feminino da Aeronáutica, regida pela CLT, em que sustentou que "descabe concluir pela legalidade do ato de desligamento quando lançado ao mundo jurídico sem qualquer motivação", 8 demonstrando um novo

7 FERREIRA, Obi Damasceno. PARECER n ${ }^{\circ}$ CQ-64. Revista de Direito Administrativo. São Paulo, v. 200, p. 249-256, abr-jul/1995.

8 RMS 21485/DF, $2^{\text {a }}$ Turma, publicado em 1\%/7/1993. 
viés de enfrentamento da questão pelo Judiciário. ${ }^{9}$

Embora se admita que o Estado, diretamente, por suas empresas ou por sociedades das quais é acionista majoritário, ao contratar pelo regime privado dispa-se das prerrogativas de império e de soberania, equiparandose ao empregador comum, tal fato não tem o condão de eximi-lo do dever de observância aos ditames publicistas, previstos no art. 37, caput, da Constituição, os quais sempre o acompanham, principalmente na prática de seus atos, nos quais se incluem os de cunho discricionário, discricionariedade esta vinculada aos princípios constitutivos do sistema jurídico, conforme magistério de Juarez Freitas. ${ }^{10}$

Ao contrário do há muito defendido, não serve como justificativa à distinção feita entre a "preservação" do emprego dos que prestam labor à Administração direta, autárquica e fundacional, em oposição aos trabalhadores das empresas públicas e sociedades de economia mista, o imperativo de permitir ao Estado uma maior agilidade para atuar no desenvolvimento de atividades econômicas, permitindo igualdade de concorrência com os particulares.
Embora o art. $173, \S 1^{\circ}$, inciso II, e $\S 2^{\circ}$, da Constituição disponha que as empresas públicas e sociedades de economia mista devam se sujeitar ao regime jurídico próprio das empresas privadas, não podendo gozar de privilégios fiscais não extensivos a estas, não se verifica a existência de qualquer oposição por tal fundamento à necessidade de contratar trabalhadores por concurso público, à realização de licitação para adquirir bens, contratar obras e serviços, à responsabilização objetiva por danos causados por seus agentes nessa qualidade e à vedação ao aumento de seus lucros "arbitrariamente", na forma disposta nos arts. 37, incisos II e XXI, $\S 6^{\circ}$ e 173 , inciso III, e $\S 4^{\circ}$, todos da lei maior.

Nota-se claramente a não configuração da alegada quebra da isonomia de condições de concorrência estabelecida entre os setores público e privado, pela exigência às pessoas integrantes daquele de motivar o ato de dispensa de seus empregados, o que poderia, com muito mais razão, decorrer do atendimento das outras exigências alinhadas.

Deve o Estado, portanto, servir de exemplo aos demais atuantes no cenário econômico, e ao próprio

9 Também do STF e do min. Marco Aurélio Mendes de Farias Mello, o seguinte precedente: "EMENTA: ESTABILIDADE-SERVIDOR PÚBLICO. A estabilidade prevista no artigo 41 da Constituição Federal independe da natureza do regime jurídico adotado. Servidores concursados e submetidos ao regime jurídico trabalhista têm jus à estabilidade, pouco importando a opção pelo sistema do Fundo de Garantia do Tempo de Serviço". (RE 187229/PA, $2^{\mathrm{a}}$ Turma, publicado em 14/5/1999).

10 FREITAS, Juarez. Estudos de Direito Administrativo. São Paulo: Malheiros, 1997, p. 135 et seq. 
Congresso Nacional, demonstrando que a proteção da relação de emprego contra a despedida arbitrária ou sem justa causa, nos moldes preconizados pelo art. $7^{\circ}$, inciso I, da Carta Política, há quase dezessete anos carente de regulamentação, não compromete ou impede o desenvolvimento com êxito de qualquer atividade produtiva, servindo, ao revés, como um meio de fazer valer a função social das empresas, expressão que congrega as figuras da propriedade e dos contratos.

Quer pela adoção ampla e irrestrita a todos os empregados públicos do disposto na Lei $\mathrm{n}^{\circ} 9.962 / 00$, por uma interpretação analógica, pautada no princípio isonômico inscrito no art. $5^{\circ}$, inciso II, da Constituição, quer por uma análise harmonizadora dos valores tutelados pelos Direitos Administrativo e do Trabalho, também em sede constitucional, ou ainda, por uma leitura moderna dos vetores disciplinadores das relações contratuais à luz do atual Código Civil, mostra-se premente uma reavaliação do entendimento majoritário e consagrado, de modo a resguardar minimamente o posto de trabalho do empregado de empresas públicas ou sociedades de economia mista. Esclareça-se, por relevante, que não se está defendendo a aplicação do disposto no art. 41 da Constituição a todo e qualquer trabalhador vinculado à Administração, que ingresse em seus quadros pela via do concurso público. Ao contrário, busca-se apenas atenuar o abismo de contradições gerado a partir da contemplação de uma "estabilidade no emprego" singular aos empregados da Administração direta, autárquica ou fundacional e, em situação diametral, de ostracismo e abandono daqueles que, de modo desavisado, prestaram concurso e foram aprovados, para laborar para empresas públicas $\mathrm{e}$ sociedades de economia mista.

\section{CONCLUSÃO}

O Estado, mesmo na condição de empregador, prestando serviços públicos ou desenvolvendo atividade econômica, encontra-se sujeito aos princípios da Administração Pública, inscritos no art. 37, caput, da Constituição, como os da Legalidade, Moralidade e Impessoalidade, os quais devem ser ponderados, em tais situações, com aqueles que orientam o Direito do Trabalho.

Inexiste, sob tal ótica, a possibilidade da prática de ato administrativo discricionário, como expressão da autonomia de vontade do agente, sob risco de configuração de arbítrio ou de desvio de finalidade, ambos contrários ao interesse público, em prejuízo à toda sociedade.

Devem, portanto, ser reavaliados os entendimentos doutrinário e jurisprudencial assentes, de que a dispensa dos empregados públicos vinculados a empresas públicas ou sociedades de economia mista prescinde de motivação, ao contrário da situação em que a contratação se dá por algum ente integrante da Administração direta, autárquica e fundacional. 
Tanto pela observância das disposições aludidas, quanto pela adoção do princípio isonômico e dos vetores que disciplinam as relações contratuais à luz da moderna teoria dos contratos, urge repensar o trato até então dispensado ao tema, a fim de resguardar minimamente o posto de

\section{REFERÊNCIAS}

BANDEIRA DE MELLO, Celso Antônio. Curso de Direito Administrativo. São Paulo: Malheiros, 2001. BONAVIDES, Paulo. Curso de Direito Constitucional. São Paulo: Malheiros, 2002.

CAMINO, Carmen. Direito Individual do Trabalho. Porto Alegre: Síntese, 2003.

FERREIRA, Obi Damasceno. Parecer $\mathrm{n}^{\circ}$ CQ-64. Revista de Direito Administrativo. São Paulo: v. 200, abr-jul/1995.

FREITAS, Juarez. Estudos de Direito Administrativo. São Paulo: Malheiros, 1997. trabalho do empregado público não ligado à Administração direta, autárquica e fundacional, exigindo-se a motivação fundamentada do ato de sua despedida, sob risco de nulificá-lo, de modo a permitir o exercício do direito à ampla defesa.

ROCHA, Manuel Alfredo Martins e. Servidor Público: empregado estabilidade no emprego de trabalhadores nas empresas estatais - abuso de poder - atos nulos e atos anuláveis. Revista do Tribunal Regional do Trabalho da $16^{a}$ Região, São Luis, v. 2, n. 1, jun/1993.

SANTOS, Boaventura de Sousa. Para um novo senso comum: a ciência, o direito e a política na transição paradigmática. São Paulo: Cortez, 2001 , v. 1 - A crítica da razão indolente: contra o desperdício da experiência. 